\title{
Structural Powers and the Homeodynamic Unity of Organisms
}

\author{
Christopher J. Austin and Anna Marmodoro
}

\begin{abstract}
Although they are continually compositionally reconstituted and reconfigured, organisms nonetheless persist as ontologically unified beings over time - but in virtue of what? A common answer is: in virtue of their continued possession of the capacity for morphological invariance which persists through, and in spite of, their mereological alteration. While we acknowledge that organisms' capacity for the "stability of form" - homeostasis - is an important aspect of their diachronic unity, we argue that this capacity is derived from, and grounded in a more primitive one - namely, the bomeodynamic capacity for the "specified variation of form". In introducing a novel type of causal power - a 'structural power' - we claim that it is the persistence of their dynamic potential to produce a specified series of structurally adaptive morphologies which grounds organisms' privileged status as metaphysically “one over many" over time.
\end{abstract}

Each biological denizen that populates our humble neighbourhood of the cosmos is a veritable world unto itself whose complex construction autonomously navigates the development and maintenance of its own intricate machinery. And although composed of an uncountable number of constituents, each of these multilayered microcosms is a fundamentally unified being - each is in some way one, rather than many. But in virtue of what, metaphysically, are organisms more than merely bundles of biological bits whose diachronically disparate collections are continually washed away in a Hericlitean flux? In other words, what secures, metaphysically, an organism's continued persistence as one over time?

In this chapter, we present an account of organismal unity centred on a neo-Aristotelian conception of causal powers, introducing a novel type of power - a 'structural' power. In examining the empirical data of contemporary developmental biology, we make a transcendental case to show that structural powers are no mere philosophers' fancy, but rather are an integral ontological feature of unified, living beings hypothesising their existence fills what would otherwise remain a glaring explanatory gap. The unique teleological nature of these powers, we argue, enables them to function as the proper metaphysical ground of the unity of organisms. According to our account, that unity is displayed not in the capacity of an organism to sustain the diachronic stasis of its morphological features (and their constituents), but in the persistence of its specified capacity for the dynamically adaptive re-organisation of those features.

\section{To Be One: A Dynamic Disposition}

If the mereological complexities involved in determining whether and under what conditions artefacts possess sufficient unity to be admitted into our ontology are overwhelming, the question of in virtue of what biological organisms enjoy that metaphysical status is even more so. The composition of something as simple as a common fruit fly, for instance, consists in an intricate hierarchy of causal-cum-functional dependence that holds among a multitude of anatomical and eidonomical levels of organisation. And what is perhaps more puzzling is the fact that whatever complex relation or set of relations is ultimately responsible for grounding the synchronic unity of these compositional elements - that is, at any particular point in time during an organism's existence - is plausibly incapable of performing that role diachronically, and for an important 
This is a pre-print version of Structural Powers and the Homeodynamic Unity of Organisms, to appear in Neo-Aristotelian Perspectives on Contemporary Science, Routledge (2017)

reason: those constituents, and thus whatever their relations' putative contribution in establishing the unity of an organism may be, are largely temporally transient. For living entities, characteristically, are loci of constant material exchange, their bodies never remaining strictly mereologically identical even over the smallest timescales. ${ }^{1}$

Thus the problem of accounting for the diachronic unity of organisms is one importantly distinct from that of accounting for their synchronic unity. The unity which organisms possess at any time might be grounded in the obtaining of a specialised spatial-cum-causal relation (or set of relations) which holds among the members of its constitutive mereological make up or, perhaps in a more sophisticated account, by those members' unified achievement of a particular functional organisation. But the problem of accounting for the unity of an organism over time concerns the significantly more complex issue of determining what the unity of those synchronically unified temporal stages consists in. To our minds, the hurdle at which existing accounts of the unity of organisms fall is that they fail to recognise that there is an important distinction between the unity which materially constituted mereological sums - elaborately and complexly structured as they may be possess and that which belongs to organisms: the diachronic unity of the former, but not the latter, consists in nothing more than the temporally successive invariance of whatever it is that grounds its synchronic unity - its mereological members retaining the same spatial-cum-causal structure, or functionally oriented organisation, etc. Organisms, on the other hand, diachronically persist in spite of the alteration over time of the structural organisation, or functional orientation of their mereological make up: whatever it is that grounds their being one at a time therefore cannot also ground their being one over time.

We know, however, that certain sets of temporally successive synchronically unified mereological collections do make up single organisms - but in virtue of what? In order to provide an answer here, a natural preliminary question is: on what are our judgments of the diachronic unity of organisms based? Prima facie, we make those judgments because although the compositional elements of organisms may be transient, their morphological profiles - that is, their general anatomical and eidonomical structures - are surprisingly diachronically stable. Plausibly then, the ontologically privileged status which we recognise that organisms enjoy is one conferred upon them primarily in virtue of their being invariantly disposed to continually maintain the causal production of their particularised morphology. It is in this respect then that organisms remain one even in the face of multiplicity: they exhibit a singular dynamically coordinative impetus which shapes the compositional character of a multitude of distinct, synchronically unified mereological collections over time. Thus, in the case of organisms, we propose that the diachronic unity which a set of those collections possesses consists in their members being subsumed within the operation of a complex teleological structure which we call a 'structural power'. ${ }^{2}$ On the account we will offer, the unity of an organism consists in the persistence of the activity of its structural power which, in spite of the continual flux of its mereological make up and so, the continual alteration of its synchronically unified composition, consistently causally conforms the shape and structure of its morphology.

More specifically, the function this power performs consists in continually organising the constituents of an organism (both anatomically and eidonomically) in a specific structural arrangement to

\footnotetext{
${ }^{1}$ Incorporating the ontological consequences of this phenomena into our organism concept is a central motivation for adopting a 'process ontology' in the philosophy of biology, a framework which is currently experiencing a slight revival. See Dupré (2013), and Jaeger and Monk (2015).

2 The notion of a 'structural power' was first introduced within a synchronic context by Marmodoro (2017).
} 
This is a pre-print version of Structural Powers and the Homeodynamic Unity of Organisms, to appear in Neo-Aristotelian Perspectives on Contemporary Science, Routledge (2017)

produce and maintain the complete morphological profile particular to the natural kind to which it belongs. ${ }^{3}$ Structural powers, to put it another way, are causally responsible for the developmental specifications of an organism's parts (which ones get produced, and by what means), and the structural complexities of their arrangement (the three-dimensional architecture of their modular components, and their spatio-functional relational hierarchy). Importantly however, although the particularised organisational complexity of an organism's morphology at any time certainly results from the causal operation of a structural power, it would be a mistake to identify any specific structural relation (or complex set thereof) among an organisms constituents with the manifestation of that power. ${ }^{4}$ Instead, we propose that the manifestation of a structural power consists in a kind of self-directed activity: the goal toward which they are teleologically directed just is the performance of their unification role in the structural organisation of an organism's elemental constituents over time, the natural result of which is those constituents (synchronically) composing a particular morphological profile. Structural powers are therefore intrinsically dynamic - like any dispositional property they are defined by what they do, but unlike most causal powers which are individuated by their role in the production of some further state, what they do is doing. ${ }^{5}$

But what exactly do structural powers do in order to function as the ground of the diachronic unity of organisms, and in what sense is that function self-directed? ${ }^{6}$ We propose that the self-directed unifying role of structural powers consists in a kind of specialised cyclopoietic (literally "cyclically-productive") activity: ${ }^{7}$ in traversing a kind of causal loop among the constituents of an organism, each is tied together in a continual diachronic cycle of co-production and maintenance. ${ }^{8}$ According to our account, the manifestation of a structural power is the causal integration among an organism's constituents wherein each contributes to the generation and proper functioning of one another in the service of their cooperative construction of a particular organismal morphology. The self-directedness of structural powers therefore consists in the recursive nature of this unifying activity - they are "self-oriented" precisely because the goal of that activity is to establish the cyclical perpetuation of its own operation. ${ }^{9}$ This operationally dynamic conception of organismal

\footnotetext{
${ }^{3}$ For the application of some of the concepts discussed in the later sections of this paper to a discussion of biological 'natural kinds', see Austin (2016).

${ }^{4}$ If it were, an organism with a divergent morphology (on account of a deformity caused by a developmental deficiency, for instance) would therefore fail to manifest its structural power, and so fail to properly unite its constituent constituents into one entity - but this is false: abnormality does not a multiplicity make. Furthermore, this sort of view would also plausibly entail that the full exhibition of its causal role would amount to it ceasing to function at some point. But this cannot be for, as Aristotle recognised, when that activity ceases, so too does the entity it belongs to; see, for instance, On the Parts of Animals I.1, 641a18-21.

5 These powers thus encapsulate the central sense of Aristotle's notion of 'actuality' / 'energeia' (literally, "being in work") in Metaphysics IX. See Charles (2010) for an excellent recent discussion.

${ }^{6}$ It's worth noting that Rea (2011) too offers an account of the diachronic unity of entities which is grounded in the activities of causal powers. However, it is one fraught with substantial difficulties of various kinds - see Marmodoro (2013).

7 The term 'cyclopoietic' is meant as a nod toward Maturana \& Varela's (1980) influential coinage of the term 'autopoietic', used to describe organisms as "self-building". We note in passing that Aristotle made use of this same criterion for distinguishing between organisms and 'artefacts', claiming that only the former possessed a 'principle of its own production' (Physics II.1, 192b29-34).

8 The function which structural powers perform is thus the embodiment of Aristotle's illustrative description of the distinguishing activity of 'natural beings' - their operation is like doctors doctoring themselves (Physics II.8, 119b30-2)

${ }_{9}$ In being self-directed in this fashion, these powers are perpetually manifesting: their manifestation provides the sufficient stimulus conditions for their subsequent manifestations. See Marmodoro (2017) for more detail.
} 
This is a pre-print version of Structural Powers and the Homeodynamic Unity of Organisms, to appear in Neo-Aristotelian Perspectives on Contemporary Science, Routledge (2017)

unity, now enshrined in the tenets of 'systems biology', ${ }^{10}$ has long been recognised as a mark of the unique ontological status which organisms qua living beings possess. ${ }^{11}$ In giving a metaphysical analysis of organismal unity, we propose then that the ontological boundaries of the causally iterative processes of generation, regeneration, and auto-regulation which sculpt the joints of the denizens of the natural world are themselves carved-out by the dynamic activity of structural powers.

Nowhere is the teleological dynamism of structural powers more prevalent than in the homeostatic phenomenon of generative robustness, where the constituents of an organism are diachronically redirected toward the reproduction of a particular morphological structure in response to perturbation. As a homeostatic phenomenon, the processes which characterise generative robustness are both persistent - able to maintain the causal production of an end-state by means of compensatory changes within the system - and pleonastic - able to bring about an end-state via a number of alternative pathways. ${ }^{12}$ 'Generative robustness', a phenomenon acknowledged to be both nearly ubiquitous in the biological realm ${ }^{13}$ and a sine quo non of the evolutionary process, ${ }^{14}$ encompasses two closely related types of homeostatic processes: redundancy and degeneracy. ${ }^{15}$ In the event that the causal architecture of a biological system malfunctions due to the (ontological or functional) uncoupling of one of its constitutive members from the others, its proper functioning in producing a particular end-state can be restored in virtue of its possessing isomorphic 'redundant' elements which take-up the slack of the missing/disabled ones. ${ }^{16}$ More interesting perhaps are cases of degeneracy, ${ }^{17}$ where homeostasis is achieved without the aid of duplicate elements, but by biological systems "re-wiring" their causal-cum-regulatory architecture in such a way that its non-isomorphic elements become isofunctional (with respect to the "missing" element), thereby causally mirroring the required role within the perturbed network. ${ }^{18}$

As we see it, properly accounting for the phenomenon of generative robustness - one wherein while the constituents of an organism (and thus the character of its synchronic unity) may undergo significant variation over various timescales, the causal orientation of its organisation toward the production and maintenance of a particular morphology does not - is a job which requires the resources of our metaphysical toolbox: the continual binding together of the compositional elements of an organism toward a particular

${ }^{10}$ Huang and Wikswo (2006); Jaeger and Monk (2015); Bich (2016).

11 Arguably it was this very sense of unity that Kant had in mind when discussing the intrinsic 'natural purpose' that sets organisms apart from matter in the Critique of Judgment; see Weber \& Varela (2002) for a comprehensive historical discussion, and Walsh (2006) for a contemporary application of this Kantian schema. For more generalised contemporary discussion of 'living beings' as unified dynamically, see Ruiz-Moreno et al. (2004), Cornish-Bowden (2006), and Razeto-Barry (2012).

12 These characteristics are derived from the influential account of Sommerhof (1950). See also Nagel (1977) and, more recently, Walsh (2012).

13 Greenspan (2001); Kitano (2004); Mason (2010).

14 Edelman and Gally (2001); Whitacre and Bender (2010).

15 Occasionally the phenomenon of 'buffering', wherein a developmental system's production of a particular morphological feature is insensitive to a wide variation of alterations in some of its input values, is understood as an exhibition of generative robustness - e.g. in the segment polarity network (Von Dassow et al. 2000; Ingolia 2004). However, as robustness via causal parameter insensitivity isn't relevant to our discussion, we have refrained from including it here.

16 Zhenglong et al. (2003); Frankel et al. (2010); MacNeil and Walhout (2011).

17 This type of 'degeneracy' is of course importantly distinct from the variety that holds between DNA codons and amino acids which refers to the merely static measure which reflects the fact that the number of unique possible combinations of the former outstrip the number of unique possible types of the latter.

18 Edelman and Gally (2001); Conant and Wagner (2004); Whitacre and Bender (2010). 
This is a pre-print version of Structural Powers and the Homeodynamic Unity of Organisms, to appear in Neo-Aristotelian Perspectives on Contemporary Science, Routledge (2017)

anatomical and eidonomical organisation over time is an expression of the causal architecture established by the cyclopoietic activity of structural powers. It is our claim that it is the persistence of this goal-directed activity which metaphysically grounds the diachronic identity of an organism: it is in virtue of the stability of its specialised dynamic operation that an organism remains one throughout the continual flux of its mereological make-up.

Importantly, the phenomenon of generative robustness suggests both what the metaphysics of the diachronic unity of organisms cannot and must consist in. With respect to the former, given that organisms persist, and persist as one throughout the exercise of such phenomena, its prevalence suggests that any metaphysical account of the diachronic unity of organisms founded on an extension of the grounds of their synchronic unity - that is, on either the persistence of a specific set of their compositional elements or some particular structural arrangement thereof - must ultimately be untenable. With respect to the latter, and given the former, the phenomenon suggests that the ontological ground of the homeostatic capacities of organisms must be extra-compositional - that is, grounded in neither the compositional elements of an organism, nor in any of their functionally unified synchronic configurations. ${ }^{19}$ In light of this, and because the nature of structural powers is principally programmatic - in that their activity provides a directive structure which specifies the temporal situation-sensitive succession of an organism's synchronic states - we propose that we ought to conceive of them as being encoded within organisms: present, though irreducible to any physical element, or the functional coordination of a set of such elements. We picture the structural power of an organism as its symphonic software: its conductorial activity ensures that each collection of notes (compositional elements) which are harmonised in each measure (synchronically unified, both causally and functionally) flow together over time to compose a coherent set of thematic movements (morphological features). ${ }^{20}$ While we acknowledge the novelty of this conception of the ontology of causal powers, we maintain that providing the proper ground of the homeostatic phenomena exhibited by organisms and subsequently accounting for the diachronic unity of organisms via an appeal to the teleological directedness of their morphology requires it. ${ }^{21}$

\section{Morphological Variability and The Nature Of Structural Powers}

According to our account, the diachronic unity of an organism is secured by the persistence of the active functioning of a causal power - a 'structural power' - which is dynamically directed toward the continual productive organisation of its mereological constituents according to a particular morphological profile. We have suggested that the causal consequences of this power's activity within an organism are exhibited most clearly in the phenomenon of generative robustness, where the intransience of the tendency of an organism's mereological make-up to be reconfigured on the occasion of perturbation toward the restoration of that profile reflects the persistence of that power, and thus, of that organism as a unified being.

On our account then, an organism's remaining one over time is intimately linked with the diachronic stability of its morphological profile: the activity of one and the same structural power over time is evidenced

${ }_{19}$ This reflects the practice of contemporary developmental systems biology, where 'robustness' is often conceptualised as an irreducibly holistic and "distributive" feature of complex systems. See Wagner (2005), and Whitacre and Bender (2010).

${ }^{20}$ We aren't the first to characterise the intricate operations of living organisms via musical metaphors - see principally the famed systems biologist Denis Noble's The Music of Life (2006).

${ }^{21}$ We're acutely aware that there is a lot more that both could and should be said about the philosophical implications of these ontological claims, but as a more full discussion would take the present paper too far off course, we leave their consideration and explication for future work. 
This is a pre-print version of Structural Powers and the Homeodynamic Unity of Organisms, to appear in Neo-Aristotelian Perspectives on Contemporary Science, Routledge (2017)

by the invariance of a teleological directedness toward the same morphology. In other words, on our account, the diachronic unity of an organism is displayed in (though not strictly identified with) the unchanging specificities of its homeostatic activity. However, here we must confront an important complication for, according to contemporary research in developmental biology, there is a significant sense in which the particularities of an organism's capacity for robust re-organisation are themselves capable of changing over time. This is perhaps most strikingly illustrated in the well-studied phenomenon of 'phenotypic plasticity', exhibited in the ability of organisms to adopt a wide range of morphological variability in response to intra-/inter/extra-cellular "environmental" signalling, or causal influences. ${ }^{22}$ Such morphological variability ranges from being relatively minor as when, for instance, butterflies adopt distinct wing patterning in response to seasonal weather signals, ${ }^{23}$ to rather extreme, as displayed in water fleas' (Daphnia) development of large helmet-like spikes in response to receiving chemical signals from nearby predators, ${ }^{24}$ or in the caste system of ants, where hormonal signals distributed among a population produce radical changes in the morphology of its members, creating everything from winged and wispy drones to the thickly carpaced, reproductively charged queens. ${ }^{25}$

Given that the phenomenon of phenotypic plasticity is no conceptual outlier, but is instead acknowledged to be not only ubiquitous in the biological realm, but central to our understanding of both developmental and evolutionary processes, we must treat its theoretical consequences with ontological sincerity. ${ }^{26}$ With respect to this discussion, one in particular stands out: organisms don't have a single and unchanging homeostatically maintained morphological profile but are instead equipped with an entire 'morphospace' consisting of multiple such profiles which may be adopted and robustly maintained at various points in their lives in response to extrinsic stimuli. ${ }^{27}$ For an account of the diachronic unity of organisms like ours, in which oneness is intimately correlated with the persistence of a particularised impetus toward morphological stability, the reality of morphospaces poses a potential problem - for if the homeostatic phenomena displayed in the directedness of an organism's constituents toward the productive maintenance of a particular morphology is transient, then it seems so too must be the existence of the structural power whose cyclopoietic activity is causally responsible for that phenomena. And if that were the case, structural powers would be no more temporally stable than the constituents of an organism, and hence, no more able to ground the diachronic unity of an organism than they are.

Of course, this is only a problem for our account if a shift in an organism's exhibited morphology, and thus a corresponding alteration of its homeostatic maintenance toward a particular morphology, amounts to the corruption, or loss of its structural power. Is this a plausible inference? We think not. While we certainly don't wish to deny that there are cases where this sort of alteration is a consequence of the loss of a diachronic structural power, we recommend caution in making that judgement - for not every instance of this sort of alteration is such a case. What then are the criteria to be used in properly discerning these cases? True to our Aristotelian roots, we suggest that temporal variation in an organism's morphological profile and the homeostatic maintenance thereof amounts to the change in, or loss of its structural power just in case that variation is not "of the nature" of that power. ${ }^{28}$ Discerning what's "of the nature" of a power is no esoteric

\footnotetext{
22 Whitman and Agrawal (2009); Gilbert and Epel (2015).

${ }^{23}$ Gibbs et al. (2011).

${ }^{24}$ Laforsch and Tollrian (2004).

25 Miura (2005).

${ }^{26}$ Pigliucci (2005); Fusco and Minelli (2010).

${ }^{27}$ Rasskin-Gutman (2005); McGhee (2006).

28 'The intimate connection between non-random regularity and 'nature' is discussed at length in Aristotle's Physics.
} 
This is a pre-print version of Structural Powers and the Homeodynamic Unity of Organisms, to appear in Neo-Aristotelian Perspectives on Contemporary Science, Routledge (2017)

enterprise - it merely requires an appeal to the same standard we utilise in judgements of this sort in the empirical sciences: namely, non-random regularity. The thought here is simple: if, for any particular case, with respect to a particular structural power, the morphological divergence in question can be shown to be a nonrandom, repeatable occurrence, we have pro tanto justification for the judgement that such divergence isn't a genuine deviation from the "nature" of that power. And in phenomena of phenotypic plasticity, we can show precisely that.

In studying that phenomenon, contemporary research in developmental biology is actively engaged in discovering not only the scope and breadth of the plasticity of organismal morphology, but also the detailed mapping of the causal conditions under which that plasticity occurs within the morphologies of particular organisms. These mappings are known as 'norms of reaction', (or 'reaction norms'): drawing on a wealth of empirical data, these rather precise graphs detail the connections repeatedly and regularly observed between specific qualitative variations in an organism's morphological profile and various specific intra-/inter-/extracellular environmental conditions which that organism may be subject to. ${ }^{29}$ That one can experimentally investigate and quantifiably catalogue in a rigorous fashion the 'plastic potential' of an organism's morphology, we suggest, lends credence to the notion that a sizeable set of the "atypical deviations" from the characteristic morphological profiles associated with organisms are, strictly speaking, neither 'atypical', nor 'deviations'. ${ }^{30}$ Rather, in the parlance of our account, they ought to be understood as the non-random and regularly repeatable exhibitions "of the nature" of their structural powers.

\section{Stability Redux: Homeostasis vs. Homeodynamism}

One might reasonably ask why, as we have just suggested, one should hold that it is "of the nature" of structural powers to diachronically organise the constituents of an organism toward the generation and continual maintenance of not only a single morphological profile, but of a wider, more fine-grained set of qualitatively diverse profiles. Given the diversity inherent in plastic phenomena, would it not be just as coherent to suppose, for instance, that the lesson we ought to learn from the repeatability and regularity of these morphological variations is that a single organism reliably possesses multiple distinct structural powers at distinct times, and in distinct causal contexts? Of course, adopting such a position would call into serious question our account of the diachronic unity of organisms, wherein the temporal persistence of a single structural power functions as its ontological ground. However, we think that would be the wrong lesson to draw - and showing why that is so will allow us to further elucidate a central aspect of our account.

The reason we think one ought to hold that it is "of the nature" of a single structural power to developmentally direct the synchronic states of an organism toward multiple teleological goals is that it is the view strongly suggested by two important features which characterise this multiplicity. The first is that the

\footnotetext{
29 Schlichting and Smith (2002); Windig et al. (2004); Aubin-Horth and Renn (2009). For some recent insights into the complexities of the reaction-norm mapping of the aforementioned Daphnia, see Colbourne et al. (2011).

30 This idea that even regularly produced so-called morphological "monsters" are the results of an intrinsic generative 'logic' was championed in the context of developmental biology by Alberch (1989). We note in passing that Aristotle prefigured this reasoning in On the Generation of Animals (IV.4, 770b13-24): "Even in the case of monstrosities, whenever things contrary to the established order but still always in a certain way and not at random, the result seems to be less of a monstrosity because even that which is contrary to nature is in a certain sense according to nature...for instance, there is a vine which some call 'smoky'; if it bears black grapes, they do not judge it a monstrosity because it is in the habit of doing this very often. The reason is that it is in its nature intermediate between white and black; thus the change is not a large one nor, so to say, contrary to nature; at least, it is not a change into another nature".
} 
This is a pre-print version of Structural Powers and the Homeodynamic Unity of Organisms, to appear in Neo-Aristotelian Perspectives on Contemporary Science, Routledge (2017)

various morphologies that an organism is capable of exhibiting (and robustly maintaining) as adaptive displays of their phenotypic plasticity, qualitatively dissimilar as they may be, are causally "reachable" from one another via some series of transformations - e.g. changes in chemical thresholds, genetic expression levels, etc. Indeed, in experimental morphospace modelling, ${ }^{31}$ the exhaustive collection of these particularised morphological possibilities is conceptualised as composing a single 'landscape' whose sub-regions' distance relations reflect their relative degree of transformational accessibility from one another. ${ }^{32}$ The second feature stems from the fact that the regions of this landscape are not all created equal: some regions of that space are more heavily weighted than others. Some regions of that space, for instance, are "surrounded" by a kind of pleonastic pathing in virtue of which they have a higher probability of becoming occupied than others: the morphologies they represent are ponds into which many possible developmental tributaries flow. ${ }^{33}$ Other regions "carve-out" deep valleys which, once occupied, have a higher probability of remaining occupied: deviation from the morphology they represent via traversal to other regions on that landscape can only done with some degree of difficulty (if it all, in some cases). As we hope should by now be clear, the relative weights assigned to various regions in morphospace are measures of the robustness of the morphologies those regions represent. ${ }^{34}$ Importantly however, the degree to which each of these morphologies is generatively robust and so the extent to which they are homeostatically maintained in the event of perturbations, and thus represent significantly distinct available morphological states of an organism - can only be established as the inverse of the measure of the relative causal "strength" the organism's composition must exhibit in order to achieve the aforementioned transformation to some other morphological state.

Taking both of these features of an organismal morphospace seriously inclines us to think that the plastic potential it enshrines characterises a single structural power. For the morphological forms which comprise it are only superficially separated from one another, as no particular form within that space is an inaccessible island but rather, in forming a continuous, dynamically connected landscape, the regions which they occupy are, in a certain sense, only so many permutations of a single morphological type. We suggest then that the manifestation which defines a structural power ought to be understood as being metaphysically 'multifaceted' - that is, as consisting of a wide variety of quantitatively and/or qualitatively distinct permutations of a single manifestation-type within a wide range of causal contexts ${ }^{35}$. Of course, these permutations, and indeed, the entirety of that multifaceted landscape is only a static reflection of the dynamics which characterise the cyclopoietic activity of a structural power, mapping out, as it were, the full

31 This type of modeling has recently been extensively utilised in the study of the morphological potential of pluripotent cells - see, for instance, Bhattacharya et al. (2011), and Li and Wang (2013).

32 Wagner and Stadler (2003); Rasskin-Gutman (2005); McGhee (2006); Wagner (2014).

33 The conception of morphospace as contoured in this fashion, first proposed by Waddington (1957), is now a central pillar of the theoretical research project of evolutionary developmental biology in the form of 'developmental constraints', or 'generative bias' (Arthur 2002; Amundson 2005; Hallgrimsson et al. 2012; Brigandt 2015). For recent empirical case studies, see Young et al. (2010) and Rasskin-Gutman and Esteve-Altava (2014).

34 The representation of the probability measure of states via topological mappings is central to the now widely-employed methodology of dynamic systems theory analyses in theoretical developmental biology (Wang et al. 2011; Huang 2012; Davila-Velderrain et al. 2015), within which system state robustness is often given a topological interpretation (Kitano 2004; Huang 2009; Huneman 2010).

35 We intentionally refer to the manifestation of structural powers as 'multifaceted' - reflecting the fact that the contextsensitive manifestations it may exhibit are facets of a single surface - rather than referring to the powers themselves as 'multitrack' (Martin 2007; Williams 2011; Vetter 2013). As evidenced from the discussion below, the two conceptions are radically distinct, though we don't have the space to explore the distinctions here. 
spectrum of its contextually sensitive teleological tendency to produce and maintain the production of an entire class of morphologies. Thus, metaphysically, the manifestation-type of a structural power is defined by an entire landscape of distinct, though dynamically united morphologies, each region of which (statically) represents a contextually particularised exhibition of its characteristic cyclopoietic activity. To return to our earlier metaphor: while each particularised morphology which an organism may adopt is a kind of selfcontained harmony within its own set of measures - in that each is a quasi-independent instance of its constituents conforming to a particular functionally unified and robustly stable configuration - each is nonetheless fundamentally a derivative expression of the thematic overture of a single symphony.

Because on our account it is the persistence of the continual activity of a structural power which serves as the metaphysical ground for the diachronic unity of an organism, and given the nature of the manifestation-types which characterise those powers we have just elucidated, a central aspect of our account can now be cast in greater relief. As we have argued, fully capturing the nature of the cyclopoietic activity of structural powers requires the conceptualisation of their morphologically multifaceted manifestation-types as the emanation of the teleological texture of their dynamics. In this way we offer a novel type of account of the diachronic unity of organisms - one which is fundamentally bomeodynamic, rather than merely bomeostatic. For while our account certainly recognises the importance of the homeostatic capacity of organisms to maintain a particular morphology in the face of various perturbations of their constituents, it nonetheless views that phenomena as a kind of 'special case' of the dynamic nature of organisms: various regions in a particular morphospace will certainly be substantially weighted (in the aforementioned sense), but only relatively, and only in the context of and as a result of the dynamics of the landscape as a whole. Thus, according to our account, what "remains the same" over time in properly unified organisms their robust preservation not of a single morphological form, but rather of the dynamic specificities of their teleologically textured morphospace which encompasses the potentiality for the expression of many such forms. The diachronic preservation of that dynamic topology, we suggest, is the exhibition of the continued presence and activity of the multifaceted manifestation of a structural power, and functions as the ontological ground of the unity of organisms.

\section{Conclusion}

As Aristotle recognised, as 'substances' par exellance, organisms enjoy a unique and privileged ontological status in our world - one for which our metaphysics must account. According to Aristotle, that status is conferred on them in virtue of their possessing 'principles of activity' which allow them to persist as unified beings, metaphysically unfettered from their mereological moorings. In line with this fundamental insight, we have offered a contemporary neo-Aristotelian metaphysical account of the diachronic unity of organisms according to which that unity is conferred by the diachronic possession of a special type of causal power - a structural power - whose dynamic manifestation consists in the teleologically directive impetus toward the organisation of the temporally fluctuating members of its mereological make-up according to the specifications of a multifaceted, contextually correlative morphological repertoire. On our view, although that unity is exhibited in the persistent capacity of an organism to remain morphologically static over time, it is more fully so in the persistence of its rich dynamic capacity for a specified range of morphological variability. 
This is a pre-print version of Structural Powers and the Homeodynamic Unity of Organisms, to appear in Neo-Aristotelian Perspectives on Contemporary Science, Routledge (2017)

In this way, organisms are homeodynamic unities whose privileged position upon the ontological hierarchy is one afforded them by their possession of structural powers. ${ }^{36}$

\section{Bibliography}

Alberch, P. (1989). 'The Logic of Monsters: Evidence for Internal Constraint in Development and Evolution', Geobios, 22, 21-57. Amundson, R. (2005). The Changing Role of the Embryo in Evolutionary Thought: Roots of Evo-Devo. Cambridge: Cambridge University Press. Aristotle. (1984). The Complete Works of Aristotle (Vol. I \& II). (J. Barnes, Trans.) Princeton: Princeton University Press.

Arthur, W. (2002). 'The Emerging Conceptual Framework of Evolutionary Developmental Biology', Nature, 415(6873), $757-764$.

Aubin-Horth, N., \& Renn, S. (2009). 'Genomic Reaction Norms: Using Integrative Biology to Understand Molecular Mechanisms of Phenotypic Plasticity', Molecular Ecology, 3763-3780.

Austin, C. J. (2016). 'Aristotelian Essentialism: Essence in the Age of Evolution', Synthese, DOI: 10.1007/s11229-016-1066-4. Bhattacharya, S., Zhang, Q., \& Andersen, M. (2011). 'A Deterministic Map of Waddington's Epigenetic Landscape for Cell Fate Specification', BMC Systems Biology, 5(85), 1-11.

Bich, L. (2016). 'Systems and Organizations: Theoretical Tools, Conceptual Distinctions and Epistemological Implications', In G. Minati, M. Ambram, \& E. Pessa (Eds.), Towards a Post-Bertalanffy Systematics (pp. 203-209). New York: Springer.

Brigandt, I. (2015). 'Evolutionary Developmental Biology and the Limits of Philosophical Accounts of Mechanistic Explanation', In P. A. Braillard, \& C. Malaterre (Eds.), Explanation in Biology: An Enquiry into the Diversity of Explanatory Patterns in the Life Sciences (pp. 135-173). Springer.

Charles, D. (2010). 'Metaphysics $\Theta .7$ and 8: Some Issues Concerning Actuality and Potentiality', In J. Lennox, \& R. Bolton (Eds.), Being, Nature, and Life in Aristotle: Essays in Honor of Allan Gotthelf (pp. 168-197). Cambridge: Cambridge University Press.

Colbourne et al. (2011). 'The Ecoresponsive Genome of Daphnia Pulex', Science, 331(6017), 555-561.

Conant, G., \& Wagner, A. (2004). 'Duplicate Genes and Robustness to Transient Gene Knock-Downs in Caenorhabditis Elegans', Proceedings of the Royal Society B, 89-96.

Cornish-Bowden, A. (2006). 'Putting the Systems Back into Systems Biology', Perspectives in Biology and Medicine, 49(4), 475-489.

Davila-Velderrain, J., Martinez-Garcia, J. C., \& Alvarez-Buyila, E. R. (2015). 'Modeling the Epigenetic Attractors Landscape: Toward a Post-Genomic Mechanistic Understanding of Development', Frontiers in Genetics, 6(160), doi: 10.3389/fgene.2015.00160.

Dupre, J. (2013). 'Living Causes', Proceedings of the Aristotelian Society Supplementary Volume, 87(1), 19-38.

Edelman, G., \& Gally, J. (2001). 'Degeneracy and Complexity in Biological Systems', Proceedings of the National Academy of the Sciences, 98(24), 13763-13768.

Frankel, N., Davis, G., Vargas, D., Wang, S., Payre, F., \& Stern, D. (2010). 'Phenotypic Robustness Conferred by Apparently Redundant Transcriptional Enhancers', Nature, 466, 490-493.

Fusco, G., \& Minelli, A. (2010). 'Phenotypic Plasticity in Development and Evolution: Facts and Concepts', Philosophical Transactions of the Royal Society B, 547-556.

Gibbs, M., Wiklund, C., \& Van Dyck, H. (2011). 'Phenotypic Plasticity in Butterfly Morphology In Response to Weather Conditions During Development', Journal of Zoology, 283(3), 162-168.

Gilbert, S. F., \& Epel, D. (2015). Ecological Developmental Biology: The Environmental Regulation of Development, Health, and Evolution. Sunderland, MA: Sinauer Associates.

Greenspan, R. (2001). 'The Flexible Genome', Nature, 2(5), 383-387.

Hallgrimsson, B., Jamniczky, H., Young, N., Rolian, C., Schmidt-ott, U., \& Marcucio, R. (2012). 'The Generation of Variation and the Develomental Basis for Evolutionary Novelty', Journal of Experimental Zoology Part B Molecular and Developmental Evolution, 318(6), 501-517.

36 This collaborative research has been made possible by funding from the Templeton World Charity Foundation. We are also grateful for the feedback from the audience of our presentation of an earlier draft of this paper at Corpus Christi College, Oxford. 
This is a pre-print version of Structural Powers and the Homeodynamic Unity of Organisms, to appear in Neo-Aristotelian Perspectives on Contemporary Science, Routledge (2017)

Huang, S. (2009). 'Reprogramming Cell Fates: Reconciling Rarity with Robustness', Bioessays, 31(5), 546-560.

(2012). 'The Molecular and Mathematical Basis of Waddington's Epigenetic Landscape: A Framework for Post-Darwinian Biology?', Bioessays, 34(2), 149-157.

Huang, S., \& Wikswo, J. (2006). 'Dimensions of Systems Biology', Reviews of Physiology: Chemistry and Pharmacology, 15, 81-104.

Huneman, P. (2010). 'Topological Explanations and Robustness in Biological Sciences', Synthese, 177(2), 213-245.

Ingolia, N. (2004). 'Topology and Robustness in the Drosophila Segment Polarity Network', PLoS Biology, 2(6), 0805-0815.

Jaeger, J., \& Monk, N. (2015). 'Everything Flows: A Process Perspective On Life', EMBO Reports, 16(9), 1064-1067.

Kitano, H. (2004). 'Biological Robustness', Nature Reviews Genetics, 5(11), 826-837.

Laforsch, C., \& Tollrian, R. (2004). 'Inducible Defenses in Multipredator Environments: Cyclomorphis in Daphnia Cacullata', Ecology, 85(8), 2302-2311.

Li, C., \& Wang, J. (2013). 'Quantifying Cell Fate Decisions for Differentiation and Reprogramming of a Human Stem Cell Network: Landscape and Biological Paths', PLoS Computational Biology, 9(8), e1003165.

MacNeil, L., \& Walhout, A. (2011). 'Gene Regulatory Networks and the Role of Robustness and Stochasticity in the Control of Gene Expression', Genome Research, 21(5), 645-657.

Marmodoro, A. (2013). 'Aristotle's Hylomorphism Without Reconditioning', Philosophical Inquiry, 5-22.

(2017). 'Power Mereology: Structural Powers versus Substantial Powers', In M. Paoletti, \& F. Orilia (Eds.), Philosophical and Scientific Perspectives on Downward Causation. Routledge.

Martin, C. (2007). The Mind in Nature. Oxford: Oxford University Press.

Mason, P. (2010). 'Degeneracy at Multiple Levels of Complexity', Biological Theory, 5(3), 277-288.

Maturana, H., \& Varela, F. (1980). Autopoiesis and Cognition: The Realization of the Living. Boston: D. Reidel .

McGhee, G. (2006). The Geometry of Evolution: Adaptive Landscapes and Theoretical Morphospaces. Cambridge: Cambridge University Press.

Miura, T. (2005). 'Developmental Regulation of Caste-Specific Characters in Social-Insect Polyphenism', Evolution \& Development, 7(2), 122-129.

Nagel, E. (1977). 'Goal-Directed Processes in Biology', The Journal of Philosophy, 261-279.

Noble, D. (2006). The Music of Life: Biology beyond the Genome. Oxford: Oxford University Press.

Pigliucci, M. (2005). 'Evolution of Phenotypic Plasticity: Where Are We Going Now?', Trends in Ecology \& Evolution, 20(9), 481-486.

Rasskin-Gutman, D. (2005). 'Modularity: Jumping Forms within Morphospace', In W. Callebaut, \& D. Rasskin-Gutman (Eds.), Modularity: Understanding the Development and Evolution of Natural Complex Systems (pp. 207-219). Cambridge: MIT Press.

Rasskin-Gutman, D., \& Esteve-Altava, B. (2014). 'Connecting the Dots: Anatomical Network Analysis in Morphological EvoDevo', Biological Theory, 9(2), 178-193.

Razeto-Barry, P. (2012). 'Autopoiesis 40 Years Later: A Review and a Reformulation', Origins of Life and Evolution of Biospheres, 42(6), 543-567.

Rea, M. (2011). 'Hylomorphism Reconditioned', Philosophical Perspectives, 25(1), 341-358.

Ruiz-Moreno, K., Pereto, J., \& Moreno, A. (2004). 'A Universal Definition of Life: Autonomy and Open-Ended Evolution', Origins of Life and Evolution of the Biosphere, 34(3), 323-346.

Schlichting, C., \& Smith, H. (2002). 'Phenotypic Plasticity: Linking Molecular Mechanisms with Evolutionary Outcomes', Evolutionary Ecology, 189-211.

Sommerhof, G. (1950). Analytical Biology. Oxford: Oxford University Press.

Vetter, B. (2013). 'Multi-Track Dispositions', The Philosophical Quarterly, 330-352.

von Dassow, G., Meir, E., Munro, E. M., \& Odell, G. M. (2000). 'The Segment Polarity Network is a Robust Developmental Module', Nature, 188-192.

Waddington, C. H. (1957). The Strategy of the Genes. London: George Allen \& Unwin.

Wagner, A. (2005). Robustness and Evolvability In Living Systems. Princeton: Princeton University Press.

Wagner, G. (2014). Homology, Genes, and Evolutionary Innovation. Princeton: Princeton University Press.

Wagner, G., \& Stadler, P. (2003). 'Quasi-Independence, Homology and The Unity of Type: A Topological Theory of Characters', Journal of Theoretical Biology, 220, 505-527.

Walsh, D. (2006). 'Organisms as Natural Purposes: The Contemporary Evolutionary Perspective', Studies in History and Philosophy of Science Part C: Studies in History and Philosophy of Biological and Biomedical Sciences, 37(4), 771-791.

(2012). 'Mechanism and Purpose: A Case of Natural Teleology', Studies in History and Philosophy of Biological Biomedical Sciences, 173-181.

Wang, J., Zhang, K., Xu, L., \& Wang, E. (2011). 'Quantifying the Waddington Landscape and Biological Paths for Development and Differentiation', Proceedings of the National Academy of Sciences of the United States of America, 108(20), 8257-8262. 
This is a pre-print version of Structural Powers and the Homeodynamic Unity of Organisms, to appear in Neo-Aristotelian Perspectives on Contemporary Science, Routledge (2017)

Weber, A., \& Varela, F. (2002). 'Life After Kant: Natural Purposes and the Autopoietic Foundations of Biological Individuality', Phenomenology and the Cognitive Sciences, 1(2), 97-125.

Whitacre, J., \& Bender, A. (2010). 'Networked Buffering: A Basic Mechanism for Distributed Robustness in Complex Adaptive Systems', Theoretical Biology and Medical Modelling, 7(20), 1-20.

Whitman, D. W., \& Agrawal, A. A. (2009). 'What is Phenotypic Plasiticty and Why Is It Important?', In T. N. Ananthakrishna, \& D. W. Whitman (Eds.), Phenotypic Plasticity of Insects: Mechanisms and Consequences (pp. 1-63). Enfield: Science Publishers.

Williams, N. E. (2011). 'Putting Powers Back on Multi-Track', Philosophia, 39(3), 581-595.

Windig, J., de Kovel, C., \& de Jong, G. (2004). 'Genetics and Mechanics of Plasticity', In T. DeWitt, \& S. Scheiner (Eds.), Phenotypic Plasticity: Functional and Conceptual Approaches (pp. 31-49). New York: Oxford University Press.

Young, N., Wagner, G., \& Hallgrimsson, B. (2010). 'Development and the Evolvability of Human Limbs', Proceedings of the National Academy of Sciences, 107(8), 3400-3405.

Zhenglong, G., Steinmetz, L., Gu, X., Scharfe, C., Davis, R., \& Li, W.-H. (2003). 'Role of Duplicate Genes in Genetic Robustness Against Null Mutations', Nature, 421(6918), 63-66. 